\title{
Energy efficiency in South Africa: A decomposition exercise
}

\author{
Inglesi-Lotz, R. ${ }^{1}$ \& Pouris, A. ${ }^{2}$
}

\begin{abstract}
Improvement of energy efficiency has been accepted as one of the most cost-effective approaches towards sustainable economic development and reduction of the continuously increasing energy consumption internationally. South Africa, being among the developing countries, is not an exception even though historically low energy prices and the lack of appropriate policies have created an energy-intensive economy.
\end{abstract}

This paper examines the factors affecting the trends in energy efficiency in South Africa from 1993 to 2006 and particularly the impact of structural changes and utilisation efficiency of the country's energy intensity. Identifying and understanding the driving forces are necessary ingredients in the development of appropriate policy-making. This paper also provides disaggregation of the energy efficiency trends in the main sectors of the economy.

We determine that structural changes of the economy have played an important and negative role in the increasing economy-wide energy efficiency. On the other hand, the energy usage's intensity was a contributing factor to the decreasing trend of energy efficiency. We suggest that differentiated price policies may be required if South Africa is to create an effective energy efficiency policy.

Keywords: energy efficiency; decomposition; price policy; South Africa

${ }^{1}$ Department of Economics, University of Pretoria. Corresponding author: roula.inglesi-lotz@up.ac.za Postal address: Department of Economics, Main Campus, University of Pretoria, Pretoria, South Africa

${ }^{2}$ Institute for Technological Innovation (ITI), University of Pretoria 


\section{INTRODUCTION}

Internationally, countries are starting to face the challenge of sustainable energy. This means that their behaviour towards energy usage has to align with their social, environmental and economic targets. The improvement of energy efficiency has been accepted as one of the most cost-effective approaches towards sustainable economic development and the reduction of the continuously increasing energy consumption. Also, the environmental benefits are important: reduction of greenhouse gas emissions, $\mathrm{CO}_{2}, \mathrm{SO}_{2}$ and smoke emissions are key objectives at a local level for many communities living adjacent to heavily industrialised areas.

Both developed and emerging countries face similar energy and environmental challenges. South Africa, being among the developing countries, is no exception. Amongst its main industries in GDP are those related to minerals extraction and processing which are by nature energy intensive [1]. Even though the character of the economy is energy intensive, the historically low prices and the lack of public awareness about the consequences of extensive energy usage have provided little incentive to save energy [2, 3].

The main purpose of this paper is to unfold the reasons of the trends in energy efficiency in South Africa from 1993 to 2006; particularly the identification of the impact of structural changes and utilisation efficiency on the country's energy intensity. By identifying and understanding the driving forces, policy-makers can choose the most appropriate policies for the future of energy efficiency. This paper will also disaggregate the energy efficiency trends in the main sectors of the economy. Various sectors have different energy profiles and hence, different reasons for their change in energy efficiency [4]. Identifying these will confirm the fact that different sectors should be treated differently with regards to future policy measures.

To do so, the rest of the paper is structured as follows. Section 2 reviews international and local literature while Section 3 discusses South Africa's energy efficiency status quo. Next, the research methodology is presented in Section 4 followed by a brief discussion on the data in Section 5. The empirical results are presented in Section 6. Finally, Section 7 discusses various policy implications and concludes. 


\section{BASIC CONCEPTS}

Defining energy efficiency can prove a difficult task especially if one thinks on the various contexts within which the concept can be used. In order to come up with a definition that includes as much information as possible, the World Energy Council [5] defined it as follows:

Energy efficiency improvements refer to a reduction in the energy used for a given service (heating, lighting, etc.) or level of activity. The reduction in the energy consumption is usually associated with technological changes, but not always since it can also result from better organisation and management or improved economic conditions in the sector ("nontechnical factors").

Similarly, in the European Union's Action Plan for Energy Efficiency [6], the concept of energy efficiency is defined as "...reducing energy consumption without reducing the use of energy-consuming plant and equipment. The aim is to make better use of energy. Energy efficiency means promoting behaviour, working methods and manufacturing techniques which are less energy-intensive."

According to Oikonomou et al. [7], energy usage improvements can only be achieved either through efficiency or behavioural changes. On the same note, Bernard and Cote [8] argue that the relative changes of behaviour in production among sectors or even within sectors should be taken into account.

In general, it is agreed that energy efficiency is an economical way to reduce energy usage taking into consideration the economies' real output $[9,10]$ Knowledge of the evolution of energy intensity/efficiency is imperative because energy policy-makers should know how energy demand will increase or decrease if the economy faces critical changes in its structure and management [11]. On that note, specific attention should be given to transition economies as the energy consumption increases as the countries' output increases. Some examples of this trend are firstly South Africa's total energy consumption 
increased by $25 \%$ from 1990 to 2006 while its output by $52.6 \%$ for the same period; China's energy consumption by $76 \%$ and output $375 \%$; India's energy consumption increased by $49 \%$ while output 161\%; Brazil's energy consumption increased by $60 \%$ while its output by $52 \%$ and Mexico's energy consumption increased by $27 \%$ and its output for the same period increased by $62 \%[12,13]^{3}$.

Improving energy efficiency is an effective way for reducing greenhouse gas emissions. Also, striving for more energy efficient equipment might lead to increased competition with positive results (for consumers) in the prices of products and services [14].

\section{SOUTH AFRICAN ENERGY EFFICIENCY}

After the political instability of the 1990s and the country's first democratic elections in 1994, the priorities of the policy-makers changed. The current government has identified energy issues as critical for the economic development of the country. The Free Basic Electricity (FBE) indicates the importance of energy issues and ensures that a certain amount of electricity is provided free of charge to the population in its entirety. More specifically with regards to energy efficiency, the first White Paper on Energy Policy [15] promotes energy efficiency awareness and encourages the use of energy-efficiency practices.

Progress on energy issues has been considered unsatisfying for many years. For example, electricity demand was increasing for many years on the basis of declining real prices and in the same time the government was refusing to allow increases in generation capacity. These resulted in major electricity blackouts in the country. The Department of Minerals and Energy (DME) decided to demonstrate the importance of energy efficiency issues by releasing the first Energy Efficiency Strategy [1] of the country. This strategy serves as a policy framework towards affordable energy for all and preventing and avoiding the negative consequences of the energy usage.

\footnotetext{
${ }^{3}$ The energy consumption in the source is measured in millions of tons of oil equivalent and the output is represented as gross domestic product (GDP) using Purchasing Power Parities (PPP) in billion US \$ in constant 2000 prices.
} 
Figure 1 shows the aggregate energy intensity of South Africa from 1993 to 2006 (the study period was defined by the availability of quality data for energy consumption in the country). The trend seems to be decreasing through the years. This should not be interpreted as a reduction in the energy consumption over the studied period. Both economic output and energy consumption increased through the years but the increase in energy consumption was lower than the increase in GDP so the overall ratio decreased.

\section{Take Figure 1}

Energy efficiency, as noted earlier, is defined as the ratio between energy consumption and economic output. In other words, the value of energy intensity shows how many units of energy (in this case TJ) are consumed for the production of 1 unit of economic output (in this case $Z_{A R}^{4}$ millions). Given this explanation, the total economy decreased its energy demand to produce R1 million from $1.165 \mathrm{TJ}$ in 1993 to $0.787 \mathrm{TJ}$ in 2006 . In other words, the required energy to produce R1 million decreased by 32.44\% from 1993 to 2006, with an average yearon-year decrease of $2.83 \%$.

Taking the analysis a step further, we determine the most energy-intensive sectors in South Africa through the years. Firstly, we compare the disaggregated (per economic sector) energy consumption of the country through the years to examine if there are any structural changes among the sectors. Figure 2 presents the percentages of energy consumption of each of the main sectors in the economy: agriculture, residential, transport and total industry for the years 1995, 2000, 2007 and 2008.

\section{Take Figure 2}

From Figure 2, we can see that the industrial sector consumed the biggest proportion of energy through the years, even though its portion of energy usage declined drastically from 2000 to 2007 and 2008. Transport was also a high energy consumer through the years with a contribution that varied from 20-25\% approximately. The residential sector's energy consumption did not exceed 10\% in 1995 and 20\% in 2000 but rose to 25\% in 2007-2008.

\footnotetext{
${ }^{4}$ ZAR is the local currency for South Africa, called the South African rand.
} 
Lastly, the agricultural sector managed to decrease its contribution to the country's energy consumption from $3.5 \%$ in 1995 to only $2.7 \%$ in 2008.

The highest industrial consumers were: 'mining and quarrying' (20.4\% to the industry and $7.12 \%$ to total), 'iron and steel' (19.8\% to the industry and $6.91 \%$ to total), 'chemical and petrochemical' (9.8\% to the industry and 3.4\% to the total) and 'non-ferrous metals' ( $7 \%$ to the industry and $2.44 \%$ to total).

However, it is likely that even though a sector consumes a high share of the overall energy in the country, it can also be among the most efficient sectors. Therefore, there is a need to put the energy usage of each sector in perspective by comparing the intensities of the various sectors.

\section{Take Figure 3}

Figure 3 shows the energy intensity per sector, defined as energy usage in TJ divided by economic output in R millions for the years 1993 and 2006. In 1993, the most intensive sectors of the South African economy were 'iron and steel', 'non-metallic minerals', 'transport', 'chemical and petrochemical' and 'non-ferrous metals'. The picture has not changed drastically in 2006 with the exception of the 'transport' sector. The rest of the most intensive sectors of 1993 continued being the most intensive for 2006, as well, with 'agriculture' and 'mining' also taking places in the top intensive sectors.

'Iron and steel' and 'non-metallic minerals' sectors have shown a significant decrease in their intensity levels. This fact can be attributed to two possible reasons: either the use of more efficient technologies or the production of a mix of products that uses less energy per value . On the other hand, the 'non-ferrous metals' and 'mining and quarrying' sectors showed increases of $23 \%$ and $21 \%$ respectively.

\section{RESEARCH METHOD}

The question that arises is which factors have driven these trends in the total economy and in the individual sectors. To answer this question, we conducted a decomposition exercise. 
Decomposition techniques have become a useful tool for energy modelling and analysis over the last two decades with special focus on energy consumption and efficiency $[4,11,14,18,19$, $20,21,22,23,24]$ as well as carbon emissions $[25,26,27,28,29,30]$ or both energy intensity and emission intensity [31]. For South Africa, Inglesi-Lotz and Blignaut (2011) have used decomposition techniques to examine the factors that affected electricity consumption in the economy-wide and sectoral level. The difference in this study is that the indicator examined is efficiency (and not consumption) and secondly, the focus is on the overall energy efficiency and not particularly of electricity.

According to $\mathrm{Ma}$ and Stern [32], there are two broad categories of decomposition analysis: input-output techniques - structural decomposition analysis (SDA) - and disaggregation techniques - index decomposition analysis (IDA). The SDA can differentiate between direct and indirect energy demands while the IDA is incapable of doing so. The advantage, however, of the IDA technique is that it can easily be applied to any available data at any level of aggregation and also to data available in time series format. In this paper, we employ the IDA model owing to a lack of energy data in an input-output format; therefore, the changes are only direct without considering indirect spill overs.

Within the IDA approach, there are various methods to employ but there is no consensus as to which one is the best. We decided to follow the method proposed by Ang and Liu [33] and Ang [34] who argue that the logarithmic mean divisia index (LMDI) should be preferred to other methods for the following four main reasons:

- Perfect decomposition: the method does not allow for the existence of unexplained residuals.

- $\quad$ Path independency: the method presents symmetry between decomposition of changes in terms of ratios or differences [35].

- The ability of the method to handle zero values

- Consistency in aggregation: decomposition exercises are usually conducted in a disaggregated level and consistency allows the results to be summed at an aggregated level. 
In the literature, a number of studies [4, 14, 35] employed decomposition techniques to separate changes in energy consumption into mainly three driving factors: (i) changes in economic structure, (ii) efficiency and (iii) production. Many studies also recently used decomposition techniques to unfold the determinants of emissions' trends in countries $[25,26$, 27]. In our analysis, we use the same methodology to decompose change in energy efficiency into changes in intensity and changes in the structure of the economy, as in Choi and Ang [35]. The structural effect indicates changes in the contribution of each economic sector of the country and the efficiency effect (which is also called technology effect or intensity effect) refers to changes in the level of energy intensity. Focusing firstly on the economy-wide energy efficiency and consequently on the various economic sectors, it should be noted here that our approach is within a top-down framework. [36].

Let $E$ be the total energy consumption in an industry and $Y$ be the total industrial production in a country. Assume that there are $\mathrm{n}$ industrial sectors, and $E_{k}$ and $Y_{k}$ are the energy consumption and production level in the kth sector, respectively. Define for sector $k$ the sectoral energy intensity $I_{k}=E_{k} / Y_{k}$ and the industrial production share $S_{k}=Y_{k} / Y$. The aggregate energy intensity $I=E / Y$ can then be written as follows:

$I=\sum_{k=1}^{n}\left(\frac{E_{k}}{Y_{k}}\right) *\left(\frac{Y_{k}}{Y}\right)=\sum_{k=1}^{n} I_{k} S_{k}$

The above equation indicates that a change in I may be due to changes in the sectoral energy intensity $I_{k}$ and/or the product mix $S_{k}$. The primary objective of an energy decomposition analysis is to quantify these two effects and to interpret their energy policy implications.

Aggregate energy intensity changes, say from the base period 0 to the comparison period $t$, may be measured in terms of the ratio $I_{t} / I_{0}$ or the difference $I_{t}-I_{0}$. Each measure has its own merits. For instance, relative changes are concise, while absolute changes provide information that can be more easily understood. The chosen measure may also depend on the aggregate indicator studied. For the aggregate energy intensity, the ratio measure would probably be preferred, especially if it is given in indices. For the total national energy 
consumption which is given in a physical unit, both measures of change can easily be adopted. To study the possible linkages between the two measures in a more formal manner, we begin our discussions with the ratio measure followed by the difference measure. In our analysis we measure the changes in terms of differences.

Differentiating both sides of (1) yields:

$\frac{d I}{d t}=\sum_{k=1}^{n} S_{k} \frac{d I_{k}}{d t}+\sum_{k=1}^{n} I_{k} \frac{d S_{k}}{d t}$

Integrating both sides of $(2)$ in the interval $[0, t)$ yields:

$I_{t}-I_{0}=\sum_{k=1}^{n} \int S_{k} \frac{d I_{k}}{d t} d t+\sum_{k=0}^{n} \int I_{k} \frac{d S_{k}}{d t} d t \quad \mathrm{Eq}(3)$

Where the first term on right hand side can be interpreted as the effect associated with energy intensity changes and the second term as the effect associated with product mix changes. Since (3) is given in the additive form, this decomposition scheme is also known as additive decomposition.

The mean value theorem for integral allows us to rewrite (3) as

$I_{t}-I_{0}=\sum_{k=1}^{n} S_{k} *\left(I_{k, t}-I_{k, 0}\right)+\sum_{k=1}^{n} I_{k} *\left(S_{k, t}-S_{k, 0}\right) \mathrm{Eq}(4)$

Similarly, (4) can be used with the chain linked calculation method to have the time interval as small as data permit:

$I_{t}-I_{t-1}=\sum_{k=1}^{n} S_{k, t} *\left(I_{k, t}-I_{k, t-1}\right)+\sum_{k=1}^{n} I_{k, t} *\left(S_{k, t}-S_{k, t-1}\right)$

$I_{t-1}-I_{t-2}=\sum_{k=1}^{n} S_{k, t-1} *\left(I_{k, t-1}-I_{k, t-2}\right)+\sum_{k=1}^{n} I_{k, t-1} *\left(S_{k, t-1}-S_{k, t-2}\right)$

$I_{1}-I_{0}=\sum_{k=1}^{n} S_{k, 1} *\left(I_{k, 1}-I_{k, 0}\right)+\sum_{k=1}^{n} I_{k, 1} *\left(S_{k, 1}-S_{k, 0}\right)$

Such that 


$$
I_{t}-I_{0}=\sum_{j=1}^{t} \sum_{k=1}^{n} S_{k, j} *\left(I_{k, j}-I_{k, j-1}\right)+\sum_{j=1}^{t} \sum_{k=1}^{n} I_{k, j} *\left(S_{k, j}-S_{k, j-1}\right) \quad \mathrm{Eq}(5)
$$

Equation (5) is also a prototype discrete approximation formula for the continuous time model given by (3), where the asterisked variables are to be replaced by some appropriate functional forms.

Specifically for this paper, the following variables and terms are used:

- $\quad \mathrm{E}_{\mathrm{t}}$ : total industrial \& agriculture energy consumption in year $\mathrm{t}$

- $\quad \mathrm{E}_{\mathrm{it}}$ : energy consumption in sector $\mathrm{i}$ in year $\mathrm{t}$

- $\quad \mathrm{Y}_{\mathrm{t}}$ : total Industrial \& agriculture economic output in year $\mathrm{t}$

- $\quad Y_{i t}$ : economic output of sector $i$ in year $t$

- $S_{i t}:$ output share of sector $i$ in year $t\left(=Y_{i t} / Y_{t}\right)$

- $\quad \mathrm{l}_{\mathrm{it}}$ : energy intensity of sector $\mathrm{i}$ in year $\mathrm{t}\left(=\mathrm{E}_{\mathrm{it}} / \mathrm{Y}_{\mathrm{it}}\right)$

- $\quad \mathrm{EF}_{\mathrm{t}}$ : energy efficiency in year $\mathrm{t}\left(=\mathrm{E}_{\mathrm{t}} / \mathrm{Y}_{\mathrm{t}}\right)$

Total industrial and agriculture energy efficiency:

$E F_{t}\left(\operatorname{or} \frac{E_{t}}{Y_{t}}\right)=\sum_{i} \frac{E_{i t}}{Y_{i t}} * \frac{Y_{i t}}{Y_{t}}=\sum_{i} I_{i t} S_{i t} \quad \mathrm{Eq}(6)$

Change in total industrial and agriculture energy efficiency between year 0 and year $\mathrm{t}$ :

$\Delta E F_{\text {tot }}=E F_{t}-E F_{0}=\Delta E F_{\text {str }}+\Delta E F_{\text {int }} \quad \mathrm{Eq}(7)$

Where str denotes structural change and int intensity changes. Based on the approach followed by Zhao, Ma \& Hong [19] the above mentioned changes are defined as follows:

$\Delta E F_{\text {int }}=\sum w_{i t} \ln \left(\frac{I_{i t}}{I_{0}}\right) \quad \mathrm{Eq}(8)$

$\Delta E F_{s t r}=\sum w_{i t} \ln \left(\frac{s_{i t}}{s_{0}}\right) \quad \mathrm{Eq}(9)$

$\Delta E F_{\text {tot }}=\sum w_{i t} \ln \left(\frac{I_{i t} s_{i t}}{I_{i 0} S_{i 0}}\right) \quad \mathrm{Eq}(10)$

where $w_{i t}=\ln \left(E F_{i t}-E F_{i 0}\right)=\left(E F_{i t}-E F_{i 0}\right) / \ln \left(E F_{i t} / E F_{i 0}\right)$ denotes the logarithmic scheme. 


\section{DATA}

Local sources are used to obtain the required data for this analysis. Sectoral and total energy consumption is derived from the Energy Balances [16], published annually by the Department of Energy (DME). In the Energy Balances, the economy consists of five sectors (industrial, commercial, agricultural, residential and transport) disaggregated in 22 industries. Also, the total energy consumption includes consumption of the following fuel types: coal, crude oil, petroleum, gas, nuclear, hydro, geothermal, solar, renewables, waste and electricity.

The main source of information is Eskom, followed by the municipal power stations and other big industries. DME does not conduct any independent surveys or regular data audits but relies on the credibility of the data providers and the National Energy Regulator (NERSA). A quality control process is in place involving a manual data check querying when inconsistencies are observed and a subsequent review process with major local and international organisations such as the International Energy Agency (IEA) [37].

Balances are available up to year 2009 however the last couple of years may still be subject to correction and hence our sample includes the period from 1993 to 2006.

The real economic output information per sector is obtained from the Quantec databases [17].

\section{EMPIRICAL RESULTS}

Table 1 shows the annual changes in energy efficiency in a year-on-year basis. The third and fourth columns present the structural and intensity effects that have influenced the changes in energy efficiency for the studied period (1993 to 2006).

\section{Take Table 1}

As was expected for the South African economy that boomed from 1993-1994 onwards, the structural changes of the economy have played an important role in increasing the economy-wide energy efficiency. However, the energy usage's intensity was a contributing 
factor to the decreasing trend of energy efficiency. If it was not for the intensity improvements the energy efficiency would have been higher by 0.38 units for the period 1993 to 2006 (last row in Table 1).

The figures for the overall period (1993-2006) indicate that there was a decrease in the ratio of consumption over output by 0.37 (last row of Table 1). The structural changes during this period influenced the ratio positively while the changes in intensity were the driving force on the negative side. In other words, if there were no changes in the intensity of the economy the ratio would have been 0.38 units higher; however, if there were no structural changes the overall ratio would have been 0.75 units lower.

The results are graphically illustrated in Figure 4. The grey line shows the changes in energy efficiency through the years, while the bars show the direction and magnitude of the driving forces of these changes: structural changes in dark grey and intensity effect in black.

\section{Take Figure 4}

Through the years, the intensity effect was a decreasing force to the changes of energy efficiency while the structural changes "pushed" the changes higher. For example, during the periods 2002/03 and 2003/04 (as depicted in Figure 4), it can be seen that the structural and intensity effects not only had opposite directions (intensity driving the country's energy efficiency lower and structural changes driving efficiency to higher levels) but also had approximately the same magnitude. As a result, the forces cancelled each other and there was no fluctuation in the changes of energy efficiency.

Table 2 presents the results of the decomposition exercise with focus on the sectoral changes. As can be seen, there is no general rule as to whether the structural changes affected the energy efficiency of the various sectors negatively or positively. The same applies for the intensity effect. However, in the majority of the sectors the structural changes and the intensity effect influenced the energy efficiency in opposite directions.

Take Table 2 
The sector with the highest change in efficiency was 'food and tobacco'. For this sector the structural effect on energy efficiency was positive (increasing the ratio of energy consumption/output). However, it was surpassed by the high negative intensity effect of 3.418. A sector that experienced an increasing intensity effect but a decreasing structural effect was 'chemical and petrochemical'. During the studied period, if the structure of the economy had not changed the intensity of the sector would have been 0.136 higher. Another interesting example is the 'non-metallic minerals' sector: both factors were increasing driving forces to the sector's ratio of energy consumption over economic output. Exactly the opposite case was experienced by the 'construction' sector: both factors drove the ratio lower within the study period (1993-2006).

Comparing these results with international decomposition analysis, it was found that for all the member countries of International Energy Agency, both structural and efficiency changes were contributing factors to the decreasing side of the energy intensity [38]. However, in South Africa's case, confirming a priori expectations, the changes in the economic activity and structure were contributing towards the increase of energy intensity over the studied period. During this period, the country experienced a boom in its economic activity and development. This resulted in higher usage of energy and hence, higher intensity levels.

Looking at the only negative effect of the energy usage's intensity, it can be concluded that if the structure of the economy has not changed through the years, the energy intensity would probably be lower.

\section{Take Figure 5}

Figure 5 presents the actual energy intensity in South Africa during the period 1993 to 2006 in comparison with energy intensity without the effect of economic structural changes. In other words, we deducted the structural changes from the actual values of energy intensity. Hence, if there was no influence from the changes in the economic structure of the country the energy intensity would have been substantially lower than it actually was. However, the trend presents similarities between the actual position and the hypothetical case. 


\section{CONCLUSION}

The objective of this paper is to identify the factors affecting the energy intensity of the South African economy. Identification of the underlying forces affecting energy intensity is a prerequisite for the development of appropriate policy. Such information is particularly useful in developing countries where the policy and regulatory authorities make decisions in a vacuum of relevant knowledge. For example, if the reason for high energy intensity of an economy is its structure and not its energy efficiency, it will be futile to focus efforts on the latter and ignore the issue of economic structure. In this context, it should be mentioned that China has introduced a differential power pricing policy designed to discourage energy intensive industries. Since 2004, the Chinese government classified the energy intensive industries, including electrolyte aluminum, ferroalloy, calcium carbide, caustic soda, cement, steel and others, into four categories - those to eliminate, those to discourage, those to allow and those to encourage [39].

The decomposition of the energy efficiency in South Africa is instructive. While the country's energy efficiency improves (energy is used more efficiently), structural changes move in the opposite direction. It should be noted here that the structure of the economy is an endogenous process which is not solely determined by the need to save energy but other factors as well responding to overall economic efficiency within a market paradigm.

The relevant institutions in the country lack a consistent framework for planning the expansion, stability or discouragement of targeted industries. This lack of direction coupled with a lack of a differential energy pricing policy lead to structural changes which affect the country's energy efficiency adversely. To put it differently, publishing energy policies and setting energy efficiency targets have a limited effect as far as the underlying forces are not appropriately managed. Similarly, blanket price increases (the same across all sectors) not only do not optimise the price impact on the country's energy efficiency but may also lead to adverse consequences for the country's industrial structure, foreign direct investments and similar aspects. Additionally, the findings of the exercise particularly for the energy intensive 
sectors may also be related to the nature or features of the technology. Hence, besides a differentiated energy pricing regime, a higher contribution of renewable forms for the generation of energy might assist partially to tackle the problem.

The sectoral decomposition of energy efficiency in the country confirms the above arguments. Non-ferrous metals and non-metallic minerals - two of the most energy-intensive sectors - exhibit an adverse structural effect indicating an expansion in their activities during the period. The agricultural sector also presents the same trend with regards to the structural effect, although the intensity effect "pulls" the change of energy efficiency to the other direction.

The identification of energy intensity per sector is also useful for policy development. Efforts to improve energy efficiency may be more productive in sectors with high energy intensity than in sectors with low energy intensity. As seen in Figure 3, the energy intensive sectors in the county are 'iron and steel', 'non-ferrous metals' and 'non-metallic minerals'. The development of appropriate policy instruments will further require the comparison of the efficiency of the various sectors with those following international best practice abroad. Such comparisons can provide guidance on whether efforts to improve energy intensity can bring results or not. 
Appendix

Take Table A1

Take Table A2 


\section{REFERENCES}

[1] Department of Minerals and Energy (DME). (2009). Energy Efficiency Strategy of the Republic of South Africa. Pretoria: Department of Minerals and Energy.

[2] Inglesi, R. (2010). Aggregate electricity demand in South Africa: Conditional forecasts to 2030. Applied Energy, 87(1), 197-204.

[3] Inglesi, R. \& Pouris, A. (2010). Forecasting Electricity Demand in South Africa: A critique of ESKOM's Projections. South African Journal of Science, 106(1/2), 1-4.

[4] Inglesi-Lotz, R., \& Blignaut, J. (2011). South Africa's electricity consumption: A sectoral decomposition analysis. Applied Energy, 88, 4779-4784.

[5] World Energy Council (WEC). (2008). Review and evaluation Chapter 13 Definition and scope of energy efficiency. Available at: http://www.worldenergy.org/publications/energy_efficiency_policies_around_the_world_re view_and_evaluation/1_introduction/1175.asp (accessed on 30 March 2010).

[6] European Union (EU). (2006). European Union Action Plan for energy efficiency. Brussels: European Union Commission.

[7] Oikonomou, B., Becchis, F., Steg, L. \& Russolillo, D. (2009). Energy savings and energy efficiency concepts for policy making. Energy Policy, 37, 4787-4796.

[8] Bernard, J. \& Cote, B. (2002). L'intensite energetique du sector Manufacturier de 1976 a 1996. Quebec, Canada: Chaire em Economique de I'Energie Electrique GREEN. Departement d' Economique, Universite Laval.

[9] Repetto, R. \& Austin, D. (1997). The costs of climate protection: A guide for the perplexed. Washington, D.C: World Resources Institute, Climate Protection Initiative.

[10] Al-Mansour, F. (2011). Energy efficiency trends and policy in Slovenia. Energy, 36, 1868-1877.

[11] Markandya, A., Pedroso-Galinato, S. \& Streimikiene, D. (2006). Energy intensity in transition economics: is there convergence towards the EU average. Energy Economics, 28(1), 121-145.

[12] OECD (2009). Energy Balances for OECD countries. OECD: Paris.

[13] OECD (2009). Energy Balances for non-OECD countries. OECD: Paris. 
[14] Andrade-Silva, F. \& Guerra, S. (2009). Analysis of the energy intensity evolution in the Brazilian industrial sector 1995-2005. Renewable and Sustainable Energy Reviews, 13(9), 2589-2596.

[15] Department of Minerals and Energy (DME). (1998). White Paper on Energy Policy. Pretoria: Department of Minerals and Energy.

[16] Department of Energy (DoE). (various issues). Energy balances. Pretoria: Department of Energy. Available at : http://www.energy.gov.za/files/media/media energy balances.html

[17] Quantec. (various issues). Quantec Standardised Industry database. Pretoria: Quantec.

[18] Sun, J. (1998). Changes in energy consumption and energy intensity: a complete decomposition model. Energy economics, 20, 85-100.

[19] Korppoo, A.L., Vehmas, J. \& Kinnunen, M. (2008). What goes down must come up? Trends of industrial electricity use in the North-West of Russia. Energy Policy, 36(9), 3588-3597.

[20] Metcalf, G. (2008). An Empirical analysis of energy intensity of energy intensity and its determinants at the state level. The Energy Journal, 29(3), 1-27.

[21] Liddle, B. (2009). Electricity intensity convergence in IEA/OECD countries: Aggregate and sectoral analysis. Energy Policy, 37(4), 1470-1478.

[22] Mendiluce, M., Perez-Arriaga, I. \& Ocana, C. (2010). Comparison of evolution of energy intensity in Spain and the EU15. Why is Spain different? Energy Policy, 38(1), 639-645.

[23] Zhao, X., Ma, C. \& Hong, D. (2010). Why did China's energy intensity increase during 19982006: Decomposition and policy analysis? Energy Policy, 38(3), 1379-1388.

[24] Zhou, N., Levine, M. \& Price, L. (2010). Overview of current energy efficiency policies in China. Energy Policy, 38(11), 6439-6452.

[25] Bhattacharyya, S.C. \& Matsumura, W. (2010). Changes in GHG emission intensity in EU-15: Lessons from a decomposition analysis. Energy, 35(8), 3315-3322.

[26] Hammond, G.P. \& Norman, J.B. (2011). Decomposition analysis of energy-related carbon emissions from UK manufacturing. Energy, doi:10.1016/j.energy.2011.06.035.

[27] Kumbaroglu, G. (2011). A sectoral decomposition analysis of Turkish $\mathrm{CO}_{2}$ emissions over 1990-2007. Energy, 36(5), 2419-2433. 
[28] Sheinbaum, C., Ruiz, B.J. \& Ozawa, L. (2011). Energy consumption and related $\mathrm{CO}_{2}$ emissions in five Latin American countries: Changes from 1990 to 2006 and perspectives. Energy, 36, 3629-3638.

[29] Wang, W.W., Zhang, M., Zhou, M. (2011). Using LMDI method to analyse transport sector $\mathrm{CO}_{2}$ emissions in China. Energy, 36, 5909-5915.

[30] Zhao, M., Tan, L., Zhang, W., Ji, M., Liu, Y. \& Yu, L. (2010). Decomposing the influencing factors of industrial carbon emissions in Shangai using the LMDI method. Energy, 35 , 25052510.

[31] Ang, B.W. \& Choi, K.H. (1997). Decomposition of aggregate energy and gas emission intensities for industry: a refined Divisia index method. The Energy Journal, 18, 59-73.

[35] Choi, K.-H. \& Ang, B. (2003). Decomposition of aggregate energy intensity changes in two measures: ratio and difference. Energy Economics, 25(6), 615-624.

[36] Bohringer, C. (1998). The synthesis of bottom-up and top-down in energy policy modelling. Energy Economics, 20, 233-248.

Inglesi-Lotz, R. \& Blignaut, J.N. (2011) Estimating the price elasticity of demand for electricity by sector in South Africa. South African Journal of Economic and Management Sciences, 14, 449-465.

International Energy Agency (IEA). (2009). Implementing Energy Efficiency Policies: Are IEA member countries on track? Paris: International Energy Agency.

[39] Lin, B. \& Liu, J. (2011). Principles, effects and problems of differential power pricing policy for energy intensive industries in China. Energy, 36, 111-118. 


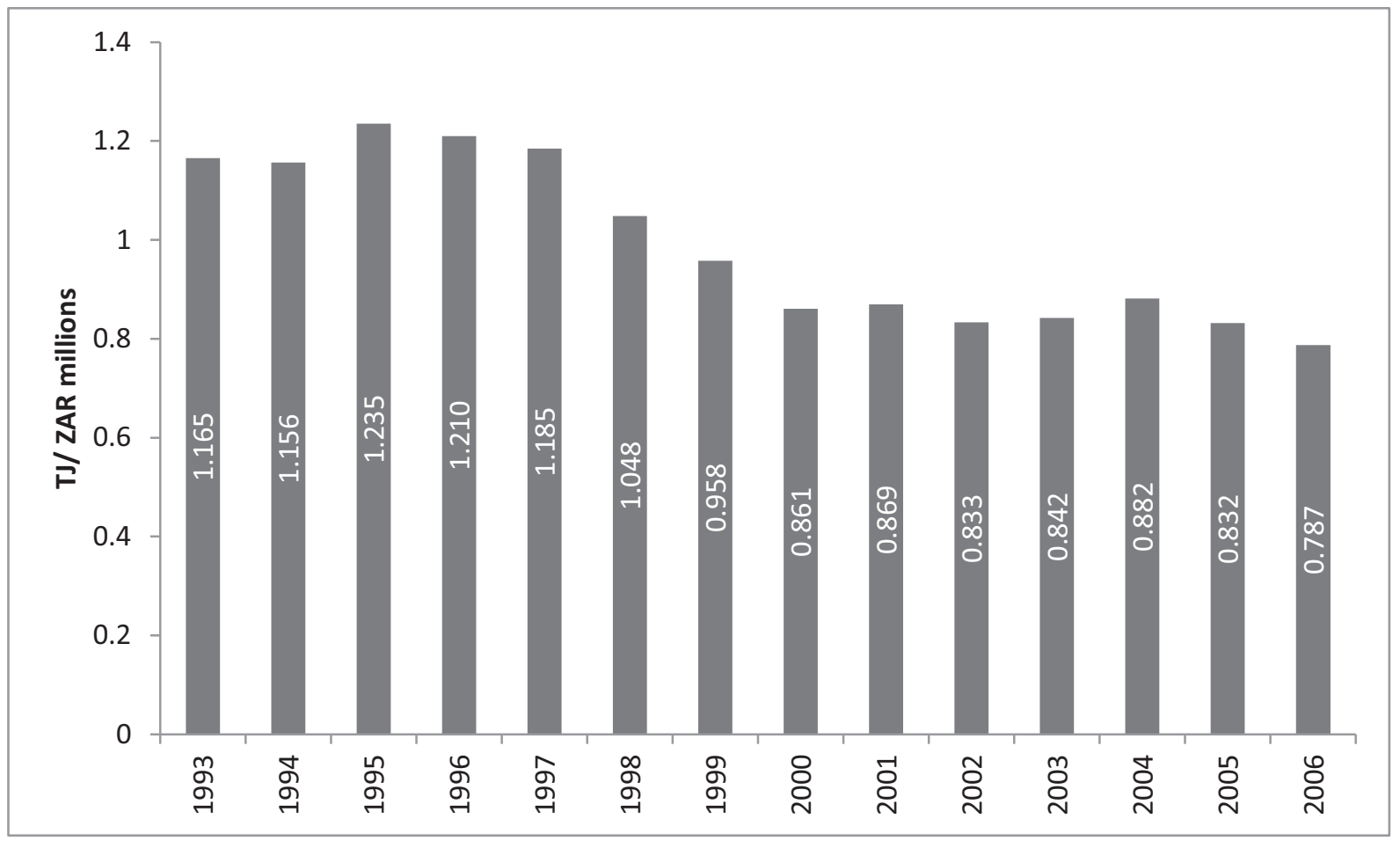

Figure 1: Aggregate energy intensity (energy consumption/GDP) in South Africa: 1993 to 2006

Source: Authors' calculations with data from the Department of Minerals and Energy (DME) [16] and Quantec [17] 


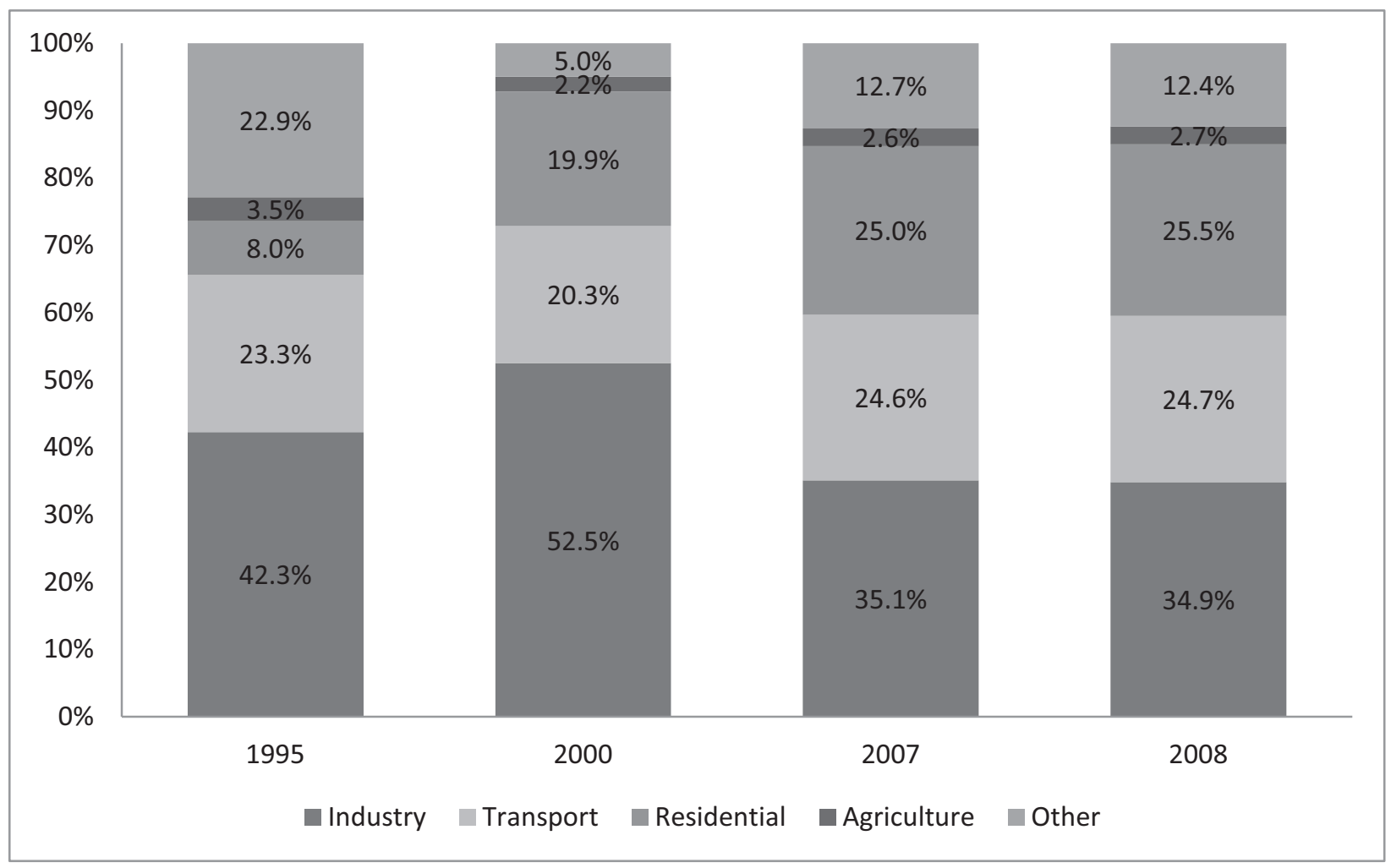

Figure 2: Disaggregation of South African energy consumption $(1995,2000 \& 2006-2008)$ Source: OECD [13] 


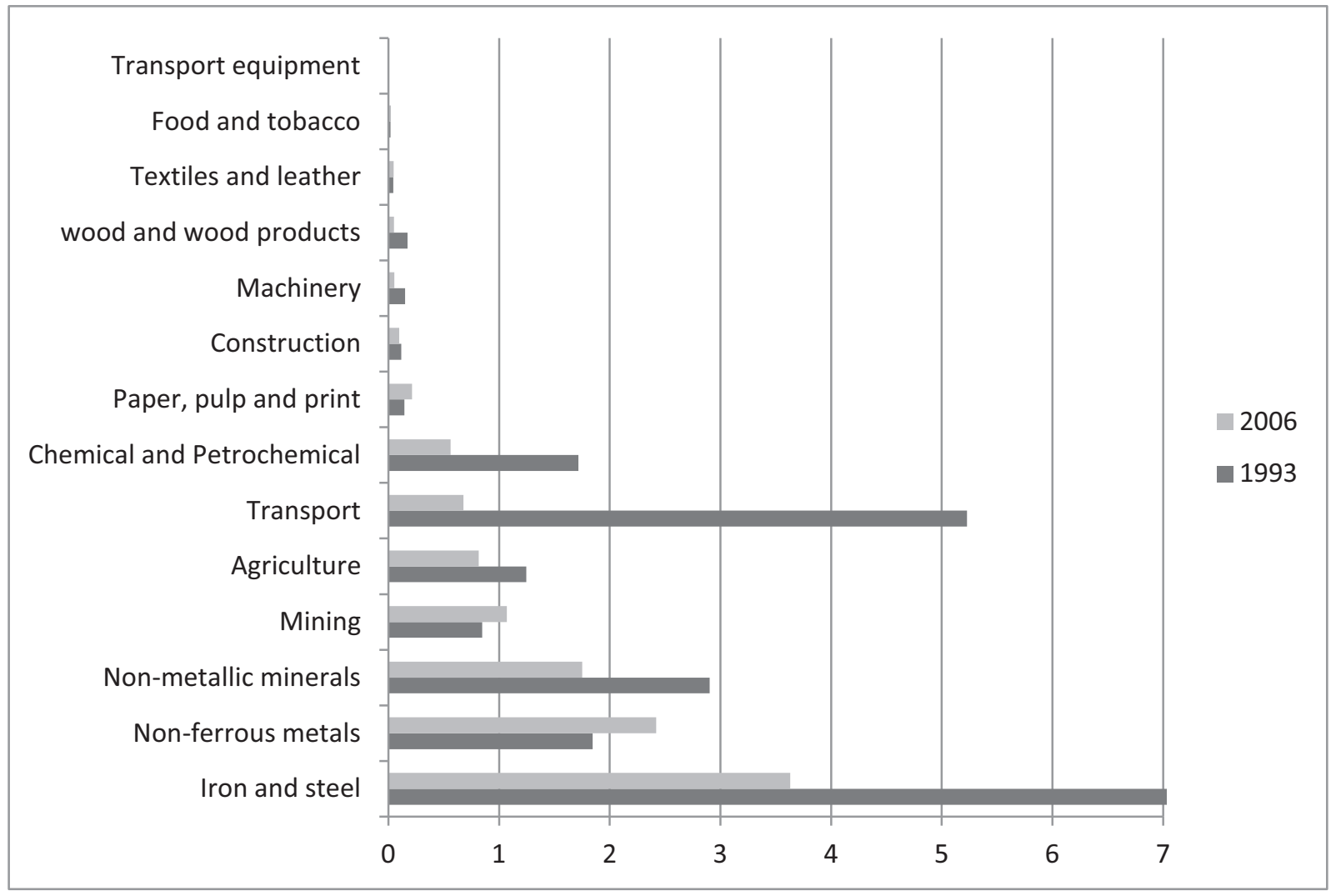

Figure 3: Energy intensity per sector in 1993 and 2006 (TJ/ZAR millions)

Source: Authors' calculations with data from DME [16] and Quantec [17] 


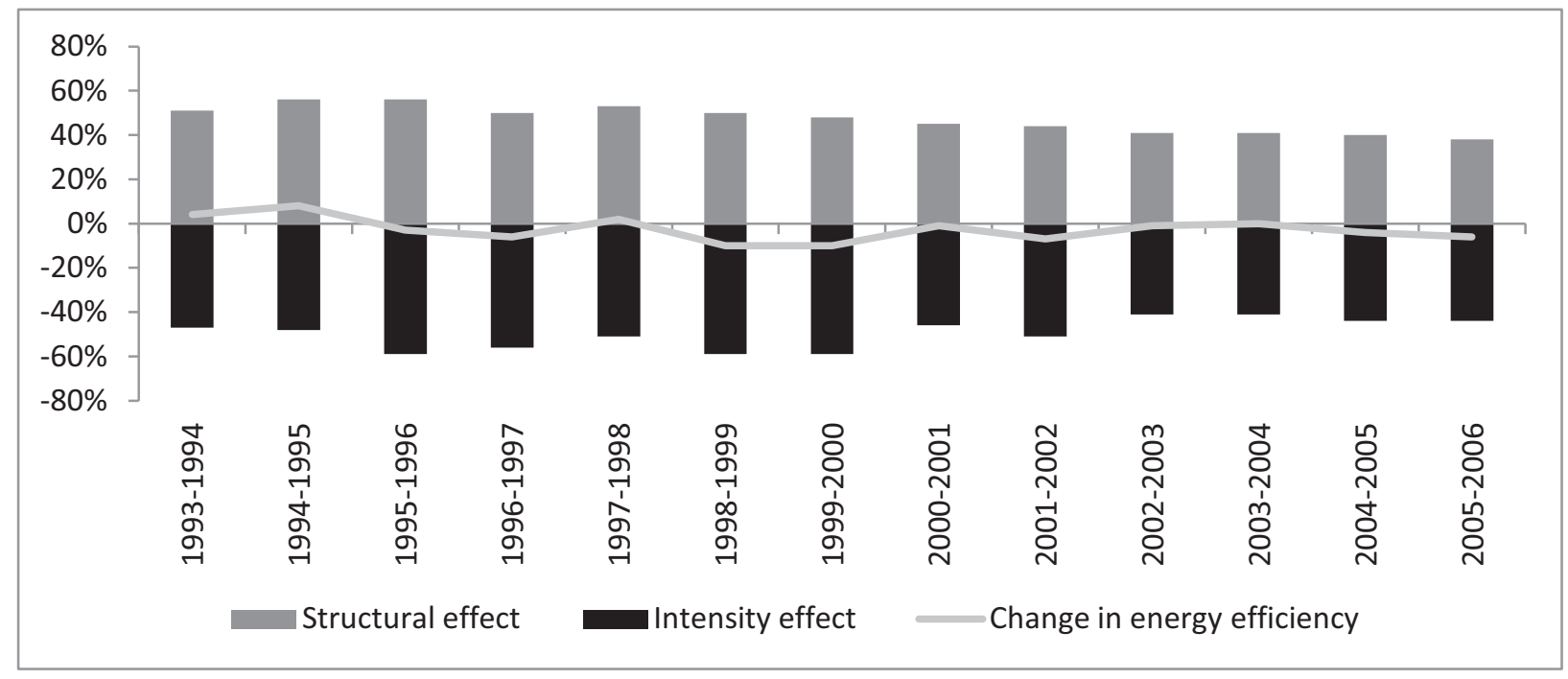

Figure 4: Decomposition of South Africa's energy efficiency changes (1993-2006)

Source: Authors' calculations 


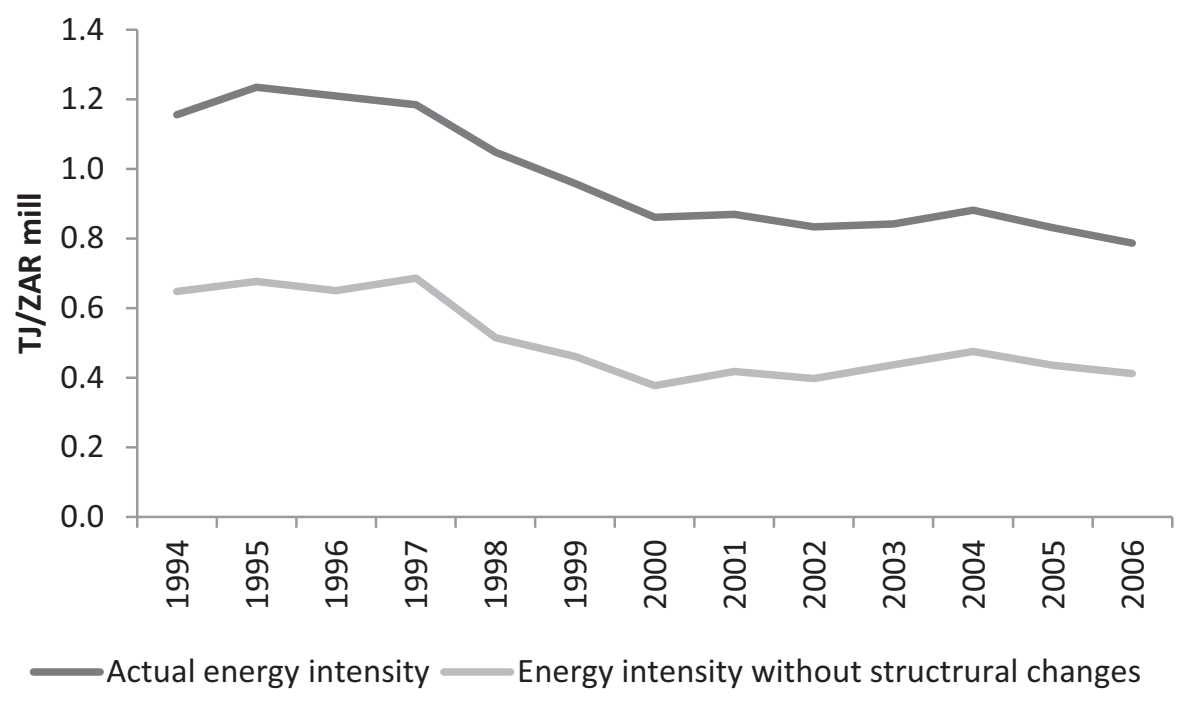

Figure 5: Actual energy intensity versus energy intensity without economic structural changes Source: Authors' calculations 
Table 1: Decomposition of South Africa's energy efficiency 1993-2006 (TJ/ZAR millions)

\begin{tabular}{|lccc|}
\hline & $\begin{array}{c}\text { Change in } \\
\text { energy efficiency }\end{array}$ & $\begin{array}{c}\text { Structural } \\
\text { effect }\end{array}$ & $\begin{array}{c}\text { Intensity } \\
\text { effect }\end{array}$ \\
\hline $1993-1994$ & 0.04 & 0.51 & -0.47 \\
$1994-1995$ & 0.08 & 0.56 & -0.48 \\
$1995-1996$ & -0.03 & 0.56 & -0.59 \\
$1996-1997$ & -0.06 & 0.50 & -0.56 \\
$1997-1998$ & 0.02 & 0.53 & -0.51 \\
$1998-1999$ & -0.10 & 0.50 & -0.59 \\
$1999-2000$ & -0.10 & 0.48 & -0.59 \\
$2000-2001$ & -0.01 & 0.45 & -0.46 \\
$2001-2002$ & -0.07 & 0.44 & -0.51 \\
$2002-2003$ & -0.01 & 0.41 & -0.41 \\
$2003-2004$ & -0.00 & 0.41 & -0.41 \\
$2004-2005$ & -0.04 & 0.40 & -0.44 \\
$2005-2006$ & -0.06 & 0.38 & -0.44 \\
\hline $1993-2006$ & -0.37 & 0.38 & -0.75 \\
\hline
\end{tabular}

Source: Authors' calculations 
Table 2: Sectoral decomposition of energy efficiency (1993-2006)

\begin{tabular}{|lccc|}
\hline & $\begin{array}{c}\text { Change in energy } \\
\text { efficiency }\end{array}$ & $\begin{array}{c}\text { Structural } \\
\text { effect }\end{array}$ & $\begin{array}{c}\text { Intensity } \\
\text { effect }\end{array}$ \\
\hline Chemical and Petrochemical & -0.424 & -0.560 & 0.136 \\
Non-ferrous metals & -0.912 & 0.244 & -1.157 \\
Non-metallic minerals & 0.890 & 0.315 & 0.576 \\
Transport equipment & -1.604 & -0.451 & -1.153 \\
Machinery & 0.000 & 0.001 & -0.001 \\
Mining and quarrying & -0.115 & -0.018 & -0.097 \\
Transport & -0.285 & -0.509 & 0.224 \\
Agriculture & -0.504 & 4.047 & -4.551 \\
Construction & -0.704 & -0.275 & -0.429 \\
Iron and steel & -0.023 & -0.004 & -0.019 \\
Food and tobacco & -2.086 & 1.332 & -3.418 \\
Paper, pulp and print & 0.001 & -0.005 & 0.006 \\
Wood and wood products & 0.063 & -0.004 & 0.067 \\
Textiles and leather & -0.122 & 0.001 & -0.124 \\
Rest of the sectors & -0.368 & 0.385 & -0.752 \\
\hline
\end{tabular}

Source: Authors' calculations 
Appendix

Table A1: South African total and sectoral energy consumption from 1993 to 2006 (measured in TJ). Source: DME [16]

\begin{tabular}{|c|c|c|c|c|c|c|c|c|c|c|c|c|c|c|}
\hline & 1993 & 1994 & 1995 & 1996 & 1997 & 1998 & 1999 & 2000 & 2001 & 2002 & 2003 & 2004 & 2005 & 2006 \\
\hline Total economy & $2,138,087$ & $2,188,534$ & $2,416,142$ & $2,395,599$ & $2,470,770$ & $2,288,502$ & $2,216,793$ & $2,193,342$ & $2,328,443$ & $2,367,890$ & $2,480,589$ & $2,717,860$ & $2,701,220$ & $2,716,381$ \\
\hline Industry and Agriculture & $1,224,100$ & $1,309,377$ & $1,443,384$ & $1,421,914$ & $1,418,396$ & $1,508,150$ & $1,470,210$ & $1,465,183$ & 1,519,199 & $1,493,520$ & $1,534,232$ & $1,599,073$ & $1,610,787$ & $1,586,971$ \\
\hline Rest of the sectors & 913,987 & 879,157 & 972,759 & 973,685 & $1,052,374$ & 780,352 & 746,584 & 728,159 & 809,244 & 874,370 & 946,357 & $1,118,787$ & $1,090,433$ & $1,129,410$ \\
\hline Chemical and Petrochemical & 189,908 & 189,206 & 260,653 & 263,189 & 253,988 & 274,462 & 264,226 & 275,002 & 235,000 & 184,584 & 178,524 & 154,006 & 141,809 & 147,625 \\
\hline Non-ferrous metals & 23,446 & 22,266 & 25,846 & 47,937 & 53,731 & 54,127 & 55,552 & 56,392 & 56,974 & 58,043 & 58,530 & 64,630 & 67,104 & 67,106 \\
\hline Non-metallic minerals & 48,243 & 59,016 & 56,619 & 42,406 & 39,136 & 44,462 & 44,596 & 43,524 & 43,406 & 43,944 & 59,019 & 67,349 & 74,818 & 44,867 \\
\hline Transport equipment & 169 & 297 & 211 & 233 & 212 & 160 & 411 & 617 & 682 & 717 & 343 & 304 & 332 & 329 \\
\hline Machinery & 4,545 & 5,230 & 5,419 & 5,148 & 5,872 & 737 & 902 & 981 & 1,010 & 1,019 & 2,337 & 2,071 & 2,278 & 2,479 \\
\hline Mining & 144,908 & 145,981 & 154,043 & 159,369 & 164,098 & 166,934 & 145,386 & 130,759 & 183,744 & 183,795 & 180,699 & 190,274 & 204,592 & 201,982 \\
\hline Transport & 484,636 & 502,798 & 563,367 & 564,195 & 583,569 & 599,766 & 605,790 & 603,985 & 620,916 & 636,332 & 656,520 & 698,552 & 710,943 & 726,596 \\
\hline Agriculture & 74,892 & 83,446 & 85,380 & 87,661 & 84,456 & 79,387 & 74,832 & 64,109 & 70,003 & 72,904 & 74,998 & 77,988 & 71,534 & 70,385 \\
\hline Construction & 10,363 & 11,438 & 12,287 & 13,651 & 14,327 & 12,078 & 10,802 & 10,671 & 15,044 & 15,816 & 16,939 & 15,982 & 16,535 & 15,665 \\
\hline Iron and steel & 233,978 & 265,341 & 267,723 & 227,226 & 206,893 & 264,916 & 254,071 & 264,322 & 277,078 & 280,727 & 292,005 & 313,771 & 305,487 & 293,426 \\
\hline Food and tobacco & 2,103 & 14,273 & 3,571 & 2,758 & 3,122 & 3,235 & 3,303 & 3,552 & 3,724 & 3,785 & 3,688 & 3,516 & 3,783 & 4,135 \\
\hline Paper, pulp and print & 3,505 & 4,603 & 3,880 & 3,875 & 4,098 & 4,113 & 6,636 & 8,344 & 8,835 & 8,837 & 7,777 & 7,697 & 8,635 & 9,441 \\
\hline wood and wood products & 1,986 & 2,361 & 2,346 & 2,397 & 3,025 & 2,413 & 2,195 & 1,553 & 1,011 & 1,115 & 974 & 1,044 & 1,068 & 1,069 \\
\hline Textiles and leather & 1,418 & 3,121 & 2,038 & 1,869 & 1,869 & 1,360 & 1,508 & 1,373 & 1,774 & 1,901 & 1,880 & 1,890 & 1,868 & 1,868 \\
\hline
\end{tabular}


Appendix

Table A2: South African total and sectoral GDP from 1993 to 2006 (measured in R millions constant 2005 prices). Source Quantec [17]

\begin{tabular}{|c|c|c|c|c|c|c|c|c|c|c|c|c|c|c|}
\hline & 1993 & 1994 & 1995 & 1996 & 1997 & 1998 & 1999 & 2000 & 2001 & 2002 & 2003 & 2004 & 2005 & 2006 \\
\hline Total economy & $1,834.96$ & $1,892.78$ & $1,956.26$ & $1,980.61$ & $2,085.41$ & $2,183.34$ & $2,314.11$ & $2,547.92$ & $2,678.94$ & $2,841.76$ & $2,946.29$ & $3,083.21$ & $3,248.15$ & $3,450.01$ \\
\hline Industry and Agriculture & 866.83 & 892.34 & 932.06 & 952.14 & 975.51 & $1,027.58$ & $1,076.56$ & $1,189.28$ & $1,244.04$ & $1,317.04$ & $1,356.81$ & $1,410.19$ & $1,464.51$ & $2,404.58$ \\
\hline Rest of the sectors & 968.12 & $1,000.44$ & $1,024.20$ & $1,028.47$ & $1,109.91$ & $1,155.76$ & $1,237.55$ & $1,358.64$ & $1,434.90$ & $1,524.73$ & $1,589.48$ & $1,673.02$ & $1,783.65$ & $1,045.43$ \\
\hline Chemical and Petrochemical & 110.61 & 116.77 & 127.97 & 131.44 & 134.54 & 158.30 & 177.63 & 210.16 & 222.14 & 228.65 & 231.83 & 238.74 & 246.89 & 263.45 \\
\hline Non-ferrous metals & 12.72 & 14.05 & 16.18 & 23.51 & 23.34 & 24.13 & 25.54 & 28.50 & 26.05 & 30.61 & 28.88 & 28.22 & 27.84 & 27.74 \\
\hline Non-metallic minerals & 16.61 & 16.48 & 17.86 & 17.91 & 17.55 & 17.31 & 16.70 & 17.63 & 18.18 & 20.80 & 21.63 & 23.08 & 24.74 & 25.63 \\
\hline Transport equipment & 52.83 & 55.63 & 66.02 & 64.33 & 62.64 & 74.39 & 83.46 & 108.26 & 131.29 & 128.68 & 130.94 & 139.39 & 150.69 & 156.28 \\
\hline Machinery & 30.32 & 29.52 & 31.77 & 33.48 & 34.65 & 34.19 & 34.43 & 36.10 & 38.86 & 43.58 & 40.01 & 42.37 & 44.69 & 46.92 \\
\hline Mining & 171.43 & 174.34 & 172.07 & 171.39 & 175.67 & 175.85 & 173.56 & 171.82 & 172.17 & 173.89 & 181.17 & 185.88 & 189.49 & 188.89 \\
\hline Transport & 92.71 & 95.98 & 100.56 & 102.95 & 107.16 & 119.28 & 131.11 & 146.88 & 152.39 & 165.90 & 175.44 & 183.25 & 187.08 & $1,074.42$ \\
\hline Agriculture & 60.16 & 64.13 & 57.59 & 66.40 & 66.46 & 68.19 & 71.26 & 73.68 & 74.20 & 81.32 & 83.27 & 84.12 & 84.52 & 86.30 \\
\hline Construction & 90.22 & 93.01 & 95.90 & 98.10 & 101.83 & 101.42 & 103.25 & 108.41 & 113.94 & 116.45 & 127.30 & 132.80 & 144.97 & 163.82 \\
\hline Iron and steel & 33.20 & 34.73 & 39.41 & 38.08 & 40.45 & 43.03 & 46.38 & 54.01 & 54.41 & 73.19 & 74.93 & 78.58 & 77.98 & 80.84 \\
\hline Food and tobacco & 126.24 & 124.57 & 128.45 & 131.34 & 134.37 & 131.86 & 130.51 & 140.54 & 147.69 & 152.29 & 159.00 & 169.73 & 180.11 & 182.59 \\
\hline Paper, pulp and print & 24.28 & 25.60 & 28.37 & 25.89 & 26.67 & 29.04 & 31.15 & 36.29 & 36.82 & 38.81 & 38.97 & 39.83 & 43.09 & 44.66 \\
\hline wood and wood products & 11.52 & 12.52 & 13.01 & 12.92 & 14.37 & 14.76 & 15.22 & 17.08 & 17.71 & 19.67 & 19.72 & 20.64 & 21.15 & 21.98 \\
\hline Textiles and leather & 33.99 & 35.01 & 36.90 & 34.42 & 35.80 & 35.82 & 36.36 & 39.92 & 38.19 & 43.21 & 43.74 & 43.55 & 41.26 & 41.07 \\
\hline
\end{tabular}

